\title{
Seasonal variation in child and old-age mortality in rural Ghana
}

\author{
Frouke M. Engelaer ${ }^{a, b, *}$, David van Bodegom ${ }^{a, b}$, Julia N. A. Mangione ${ }^{b}$, Ulrika K. Eriksson ${ }^{b}$ and Rudi G. J. Westendorp ${ }^{a, b}$

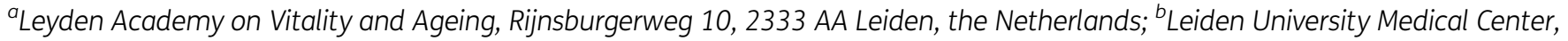 \\ Postbus 9600, 2300 RC Leiden, the Netherlands \\ *Corresponding author: Tel: +31 71 5240960; Fax: +31 71 5240969; E-mail: engelaer@leydenacademy.nl
}

Received 6 June 2013; revised 5 January 2014; accepted 8 January 2014

\begin{abstract}
Background: Mortality in tropical countries varies considerably from season to season. As many of these countries have seen mortality moving from child to old-age mortality, we have studied seasonal variation in child and old-age mortality in a rural area in Ghana that currently undergoes an epidemiologic transition.

Methods: In an annual survey from 2002 through to 2011, we followed 29642 individuals and obtained the
cause and month of death from 1406 deceased individuals by making use of verbal autopsies.

Results: When comparing the seasons, we observed a trend for higher mortality during the wet season. When comparing separate months, we observed 34\% more deaths than expected in September (95\% CI 1.04-1.69; $p=0.024)$ at the end of the wet season and 43\% more deaths in April (95\% CI 1.13-1.80; $p=0.004)$ at the end of the dry season, while there were $42 \%$ less deaths than expected in December ( $95 \%$ CI 0.52-0.70; $p=0.003$ ), shortly after the wet season. Cause-specific analysis indicated that the peak at the end of the wet season was due to excess mortality from infectious diseases in children and older people alike, whereas the peak in old-age mortality at the end of the dry season was due to non-infectious causes in older people only.
\end{abstract}

Conclusions: Taken together, our data suggest that during the epidemiologic transition, mortality not only shifts from child to old-age and from infectious to non-infectious, but also from the wet to the dry season.

Keywords: Epidemiologic transition, Mortality, Old-age, Seasonal variation, Tropical countries

\section{Introduction}

Worldwide, there is variation in mortality depending on the season. ${ }^{1-7}$ In tropical countries with a distinct dry and wet season, this is characterised mostly by excess mortality during the wet season. ${ }^{8,9}$ Most studies analysing seasonal mortality have examined these patterns only for mother and child mortality. ${ }^{10,11}$ It was found that excess mortality in the wet season is best explained by an increase in gastrointestinal infections and malaria. $^{8-11}$

Currently, many of these tropical countries are experiencing an epidemiologic transition, with mortality moving from child to oldage mortality. ${ }^{12-15}$ This is primarily due to improved living conditions and a lower risk of death from infectious diseases. ${ }^{15-17} \mathrm{At}$ the same time deaths from chronic diseases are on the rise. ${ }^{14}$ It is yet unclear how the seasonal variation in mortality has evolved now that many of these countries have undergone major changes in their mortality patterns.

In this study, we analysed seasonal patterns of mortality among children and older people from a unique population in rural Ghana, which currently experiences an epidemiologic transition. Additionally, we collected the causes of death using verbal autopsies. We first studied whether the dry and the wet season involved a proportional number of deaths and second, whether each month comprised an equal number of deaths. We stratified for age and studied the causes of death to further explore the observed patterns.

\section{Materials and methods}

\section{Study area and population}

The study was conducted in the Garu-Tempane district, which is situated in the Upper East region of Ghana. This region is far less developed than the southern part of Ghana and is highly endemic for malaria ( $85 \%$ of the population is infected with Plasmodium falciparum), typhoid fever, meningococcal disease and intestinal helminth infections. ${ }^{18-22}$ The research area was situated close to the village of Garu and measured approximately $375 \mathrm{~km}^{2}$, with almost 30000 individuals living in around 40 villages. The people in the research area lived in polygamous extended families, with an average of 15 people per household. The families lived together in compounds; which were clay structures with thatched roofs connected by clay walls. ${ }^{23,24}$ There were 1719 compounds in the research

(C) The Author 2014. Published by Oxford University Press on behalf of Royal Society of Tropical Medicine and Hygiene. All rights reserved. For permissions, please e-mail: journals.permissions@oup.com. 
area. Most people relied on traditional healers, which were equally distributed throughout the area. Although there were a few basic healthcare facilities (Community-based Health Planning and Services compounds) in the area, there were no medical doctors present, and the nearest hospital was $40 \mathrm{~km}$ away. ${ }^{21}$ The vast majority of the population were farmers and the total agricultural process was done by hand. The local economy was dominated by the barter system, where goods were directly exchanged for other goods or services. ${ }^{25,26}$ From around 1970 onwards, water boreholes that use hand operated pumps to deliver ground water, were introduced to the region. These boreholes were distributed throughout the area by a non-governmental organisation (NGO), independent of the socioeconomic status of surrounding households. Drinking water source has been accessed at the household level in 2007. In spite of the boreholes, some of the villages still depend on rainwater and water from small streams that flow through the area. Water from boreholes has been found to contain less pathogens and was considered to be safe drinking water. Water drawn from either open wells or from rivers was found to contain more pathogens and was therefore considered to be unsafe drinking water. ${ }^{22}$

\section{Climate}

The research area was characterised by a pronounced dry and wet season. The area was drier than southern areas of Ghana and was proximate to the Sahel and the Sahara. The dry season was influenced by the Harmattan, a dry and dusty desert wind that blows from the northeast. During this period the humidity was very low and rainfall was entirely absent, resulting in hot days and cool nights. The wet season was influenced by the tropical maritime air mass, which provides the area with rain. ${ }^{27,28}$ Exact data of temperature and rainfall in the research area were available from a research project between 1991 and 2004 (Ghana Government Data from the Garu Tempane district provided by Roger Blench). ${ }^{23}$ Between 1991 and 2004, the daily mean temperature was $28.5^{\circ} \mathrm{C}$. The mean minimum monthly temperature was $25^{\circ} \mathrm{C}$, whereas the mean maximum monthly temperature was $32^{\circ} \mathrm{C}$. From November to March, the minimal night temperature was $15^{\circ} \mathrm{C}$ and the maximum day temperature $45^{\circ} \mathrm{C}$. The annual mean temperature was $28.9^{\circ} \mathrm{C}$ and the annual amount of precipitation $996 \mathrm{~mm}$.

\section{Verbal autopsies}

To obtain the causes and time of death, we used the validated verbal autopsy questionnaires from the WHO. ${ }^{29-31}$ In 2011 we performed the verbal autopsies in the area to identify the causes of death in both the elderly and children. The WHO verbal autopsy method is based on a semi-structured questionnaire to conduct interviews with relatives or caretakers of deceased individuals. We translated the English questionnaires into the two major local languages: Bimoba and Kusaal. To test whether the questionnaires were translated correctly, we performed back translations by an independent translator. In cases of discrepancy, the final translation was decided upon after group discussions with native speakers and medical experts. We trained local people from the two main tribes in the area to perform the interviews with people from their tribe in the field. They were instructed to search for the most appropriate respondent, which in most cases was a relative or caretaker of the deceased. The questionnaires were systematically checked by supervisors from the field staff, who regularly also participated during the field visits. From the total of 1406 individuals that had died from 2003 to 2011 and were registered in the database, we were able to complete 1263 verbal autopsies (90\%). For the remaining 10\%, we were not able to perform a verbal autopsy interview due to various reasons, such as absence at the time of the field visit, no appropriate respondent found or in a few cases refusal to participate. Informed consent was obtained by reading the consent statement from the verbal autopsy protocol of the WHO aloud in the local language. ${ }^{29}$ Consent was documented by signature or thumbprint of the participant. The study was approved by the Ghana Health Service Ethical Review Committee. To assign the causes of death we used a physician review method. In the first round, two physicians assigned the causes of death independently, blinded from each other. The agreement of the first two physicians in assigning the causes of death was in line with other studies using verbal autopsies with an average kappa of 0.41 . If there was discrepancy between the first two diagnoses of the physicians, a third physician, who was not blinded for the diagnoses of the first two physicians, gave an independent assessment. A cause of death was determined if at least two of the medical doctors agreed, otherwise the cause of death was classified as unknown. To code the causes of death we used the International Classification of Diseases (ICD) VA-10 coding, according to the WHO verbal autopsy method. ${ }^{31}$ To study the seasonal variation in mortality we compiled the various causes of death into two categories: infectious diseases and non-infectious diseases. To test the repeatability of the verbal autopsy interviews, we performed re-interviews in a random selection of $10 \%$ of the original interviews. We tested the agreement between the diagnosis of the original interview and the re-interview and found an agreement with a kappa of 0.41 . Since a proportion of the local population is not used to using dates and months, data on the exact month of death was not always available. Therefore, we additionally added a question about the season of death (dry or wet).

\section{Socioeconomic status}

In 2007 we measured socioeconomic status at the household level using the Demographic and Health Survey (DHS) methods, specifically designed for our research area. ${ }^{32}$ First we developed a questionnaire to assess the socioeconomic status of the study participants by using a listing technique whereby we asked people from different villages of the research area, in focus group discussions, to list the household items of most value. We then applied the method used to calculate the DHS-wealth index. For analysis, the results of this DHS-wealth index were split by the median in households with low socioeconomic status (poor) and households with high socioeconomic status (rich). For a detailed description of these methods we refer to an earlier publication of this study. ${ }^{33}$

\section{Statistical analysis}

We used a Fishers exact test to assess whether the observed monthly mortality was significantly different than expected under the null-hypothesis that seasonal variation is absent. ${ }^{34}$ 


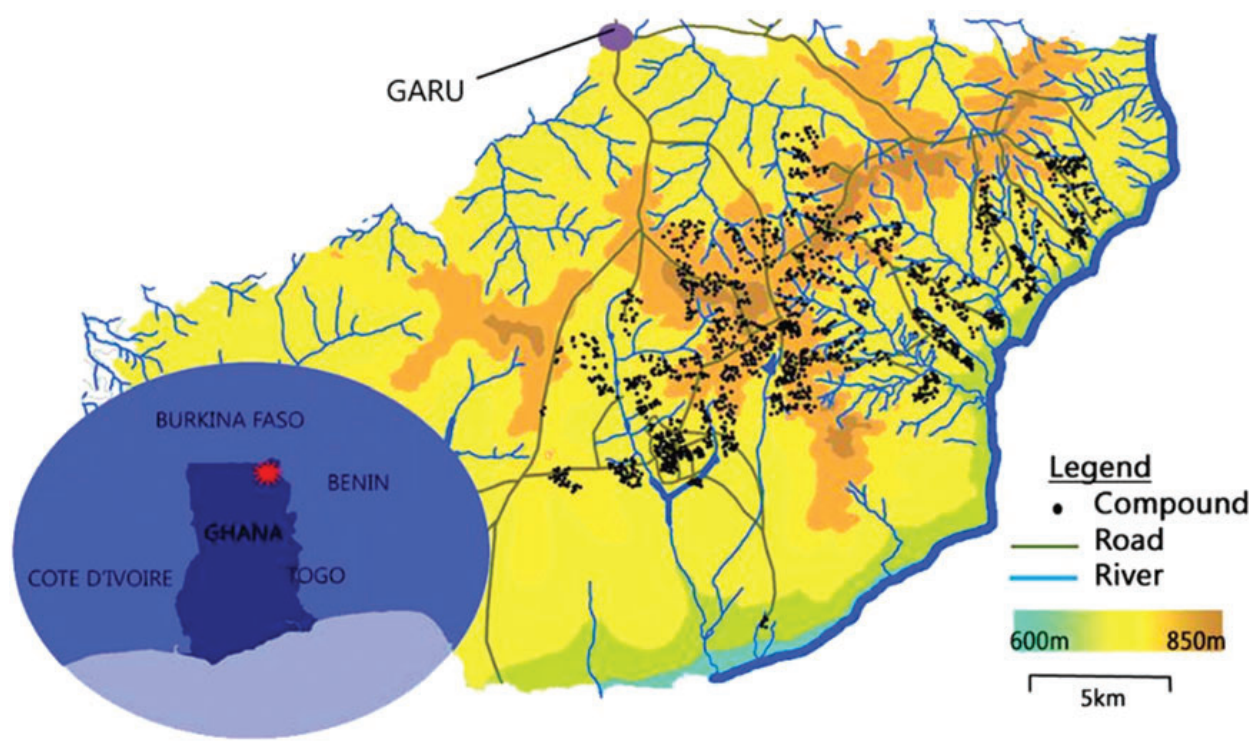

Figure 1. Map of the research area in the Upper East region of Ghana.

We calculated the confidence intervals of the count data based on a Poisson distribution. ${ }^{35,36}$ To test for agreement between physicians who assigned the causes of death, and the repeatability of the verbal autopsy interview, kappa values were calculated. All these analyses were carried out using SPSS 18 (SPSS Inc., Chicago, IL, USA). Additionally, we further analysed the data using STL: a seasonal-trend decomposition procedure based on Loess. $^{37}$ This is a filtering procedure for decomposing a time series into trend, seasonal and remainder components and was carried out in R.

\section{Results}

From 2002 through 2011 we followed 29642 individuals for mortality in the Garu Tempane District of the Upper East Region of Ghana, as shown in Figure 1. The general characteristics of the study population are summarised in Table 1 . Most individuals lived in compounds with a high socioeconomic status (61\%) and had access to safe drinking water (79\%). The Bimoba tribe was most represented (66\%), followed by the Kusasi (26\%). Other tribes, including Mamprusi and Fulani together made up to $8 \%$ of the deceased individuals.

During the period of follow-up we observed 1406 deaths, of which 56\% (786/1406) were men and 44\% (620/1406) were women. Indicative of the on-going epidemiologic transition, we observed a decline in the ratio of infectious over non-infectious causes from 1.2 to 0.7 over the 9 years observation period ( $p$ for trend 0.014). From the total of 1406 deceased individuals, we were able to obtain the season of death for 75\% (1061/1406) individuals and for $45 \%(627 / 1406)$ we could additionally obtain the exact month of death. These three groups did not differ significantly in their baseline characteristics or recall period.

The monthly variation in the average temperature and rainfall in the research area is presented in Figure 2. Temperature ranged from a mean of $26.8^{\circ} \mathrm{C}$ in August to $32.4^{\circ} \mathrm{C}$ in March and April, whereas rainfall varied from a mean of $0.2 \mathrm{~mm}$ in January and
Table 1. Characteristics of the study population from 2002 through to 2011

\begin{tabular}{lcc} 
& $\begin{array}{l}\text { Study population } \\
\mathrm{n}(\%)\end{array}$ & $\begin{array}{c}\text { Number of } \\
\text { deaths n (\%) }\end{array}$ \\
\hline $\begin{array}{l}\text { Total } \\
\text { Sex }\end{array}$ & $29642(100 \%)$ & $1406(100 \%)$ \\
$\quad$ Men & $13628(46 \%)$ & $786(56 \%)$ \\
$\quad$ Women & $16014(54 \%)$ & $620(44 \%)$ \\
Socioeconomic status & & \\
Poor & $10205(35 \%)$ & $580(41 \%)$ \\
Rich & $18414(61 \%)$ & $795(57 \%)$ \\
Unknown & $1025(4 \%)$ & $31(2 \%)$ \\
Drinking water & & \\
Unsafe & $5677(19 \%)$ & $308(22 \%)$ \\
Safe & $23428(79 \%)$ & $1095(78 \%)$ \\
Unknown & $537(2 \%)$ & $3(0 \%)$ \\
Age & & \\
Children (0-14) & $12613(43 \%)$ & $401(29 \%)$ \\
Adults (15-64) & $15369(52 \%)$ & $494(35 \%)$ \\
Elderly (>65) & $1660(6 \%)$ & $511(36 \%)$ \\
Tribe & & \\
Bimoba & $19451(66 \%)$ & $993(64 \%)$ \\
Kusasi & $7777(26 \%)$ & $918(30 \%)$ \\
Other/unknown & $2415(8 \%)$ & \\
& &
\end{tabular}

December to a peak of $263.1 \mathrm{~mm}$ in August. The area has two distinct seasons, a dry season that lasts for 7 months from October to April and a wet season that lasts for 5 months from May to September.

We first analysed the observed number of deaths per month between the wet and the dry season (Table 2). Overall there was 


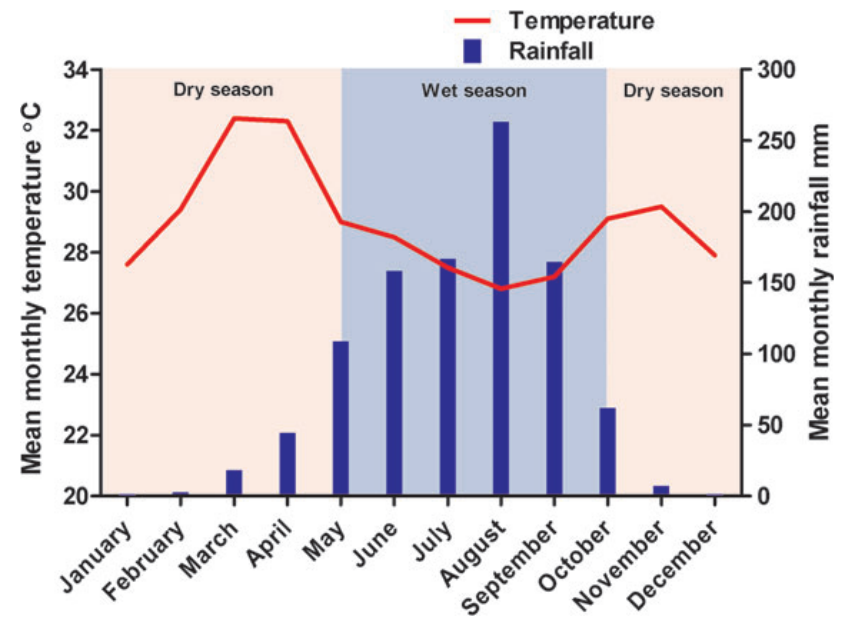

Figure 2. Climatologic variation in the research area, indicated by the mean monthly temperature and mean monthly rainfall. The annual mean temperature was $28.9^{\circ} \mathrm{C}$ and the annual amount of precipitation 996 mm. Source: Ghana Government, provided by Roger Blench.

Table 2. Number of deaths per month in wet and dry season for various subgroups

\begin{tabular}{|c|c|c|c|c|}
\hline & $\begin{array}{l}\text { Wet season } \\
\text { number of } \\
\text { deaths per } \\
\text { month }^{\mathrm{a}}\end{array}$ & $(95 \%$ CI) & $\begin{array}{l}\text { Dry season } \\
\text { number of } \\
\text { deaths per } \\
\text { month }^{a}\end{array}$ & $(95 \% \mathrm{CI})$ \\
\hline \multicolumn{4}{|l|}{ Age } & $(67-101)$ \\
\hline $\begin{array}{l}\text { Child (0- } \\
14 \text { years) }\end{array}$ & 26 & $(17-38)$ & 21 & $(14-33)$ \\
\hline $\begin{array}{l}\text { Adult (15- } \\
64 \text { years) }\end{array}$ & 33 & $(23-46)$ & 30 & $(20-43)$ \\
\hline $\begin{array}{l}\text { Old-age } \\
\text { (>65 years) }\end{array}$ & 36 & $(25-50)$ & 32 & $(22-45)$ \\
\hline \multicolumn{5}{|l|}{$\begin{array}{l}\text { Socioeconomic } \\
\text { status }\end{array}$} \\
\hline Poor & 38 & $(27-52)$ & 33 & $(23-46)$ \\
\hline Rich & 56 & $(42-73)$ & 49 & $(36-65)$ \\
\hline \multicolumn{5}{|l|}{ Drinking water } \\
\hline Unsafe & 26 & $(17-38)$ & 18 & $(11-29)$ \\
\hline Safe & 59 & $(45-76)$ & 66 & $(51-84)$ \\
\hline
\end{tabular}

a The number of deaths per month were calculated by dividing the observed number of deaths in a season by the number of months in that season.

$\mathrm{CI}=$ confidence interval.

a trend for higher mortality during the wet season. When stratifying for socioeconomic status, we observed higher mortality during the wet season in both rich and poor households. Finally, we observed that only people who made use of safe drinking water had lower mortality during the wet season.

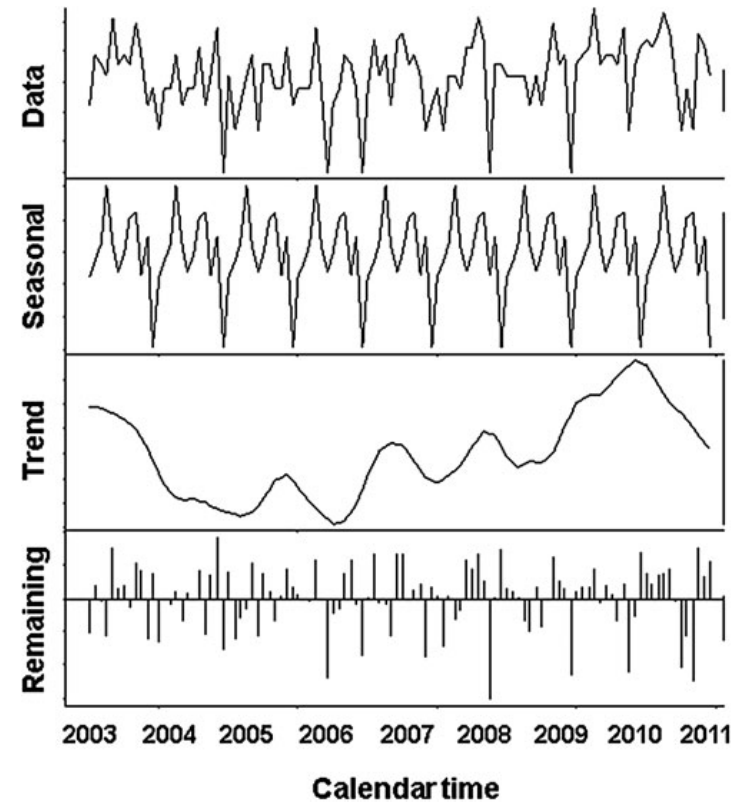

Figure 3. The seasonal variation in mortality over the months from 2003 through to 2011. This filtering procedure decomposes the raw data into a seasonal component, a trend and remaining variation.

Next, we examined the longitudinal data series in a seasonaltrend decomposition procedure. We decomposed the mortality data in a seasonal component, a secular trend and remaining variation, as shown in Figure 3. The model identified mortality peaks in April and September and low mortality in December. When comparing the separate months, we observed 34\% more deaths than expected in September (95\% CI 1.04-1.69; $p=0.024$ ) at the end of the wet season and $43 \%$ more deaths in April (95\% CI 1.13-1.80; $p=0.004)$ at the end of the dry season, while there were $42 \%$ less deaths than expected in December (95\% CI 0.52-0.70; $p=0.003$ ) shortly after the wet season. This seasonal variation overlapped for $44 \%$ with the data, while the secular mortality trend overlapped with $51 \%$ of the data. Comparing the seasonal trends over calendar time, the mortality peak in April was most pronounced in recent years (data not shown).

To further explore the causes of the seasonal variation, we stratified for child and old-age mortality. Figure 4 illustrates that child mortality shows one mortality peak during the wet season in September with $74 \%(95 \%$ CI 1.09-2.63; $p=0.021)$ more deaths than expected, whereas there was $69 \%$ fewer deaths than expected in January ( $95 \%$ CI 0.08-0.78; $p=0.007)$. In contrast, oldage mortality shows two mortality peaks: in September there were $54 \%(95 \%$ CI 1.06-2.18; $p=0.025)$ more deaths than expected and in April there were 40\% (95\% CI 1.06-2.18; $\mathrm{p}=0.098)$ more deaths than expected. In December there were 39\% less deaths than expected (95\% CI 0.32-1.04; $p=0.073$ ).

Figure 5 shows the seasonal variation in the number of deaths due to infectious and non-infectious causes. Among children (panel A), 68\% of the deaths were due to infectious diseases and appeared $75 \%$ (95\% CI 1.42-2.19; $p=0.057)$ higher in September at the end of the wet season. In January there was $66 \%(95 \%$ CI $0.19-0.59 ; p=0.048)$ mortality from infectious 


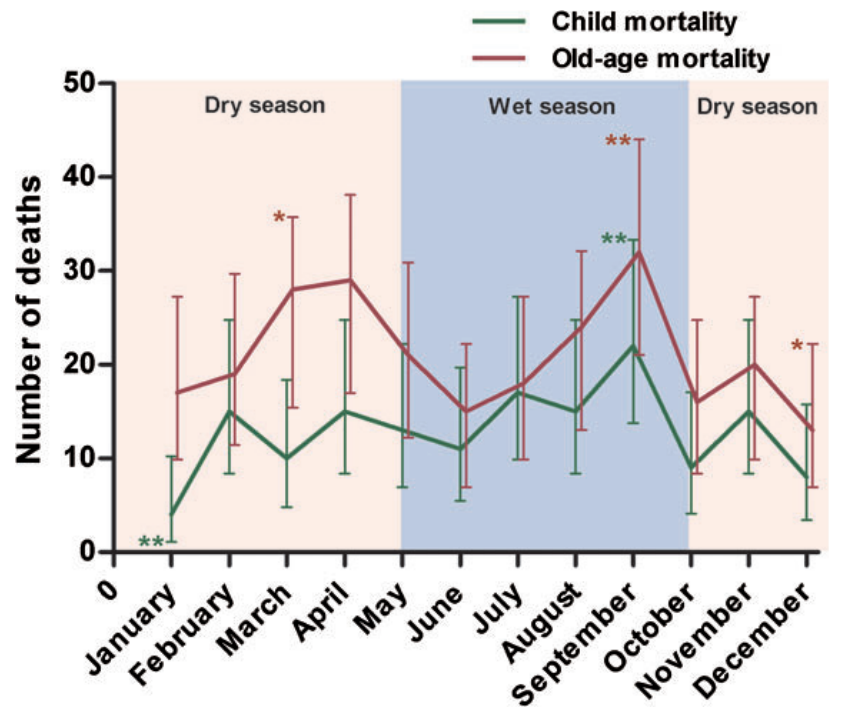

Figure 4. Seasonal variation in child mortality and old-age mortality. Mortality is expressed as number of deaths per month with error bars indicating 95\% confidence interval. Stars indicate whether the observed number of deaths in that month are significantly higher than expected. ${ }^{*} p<0.1,{ }^{* *} p<0.05$.

diseases. Mortality from non-infectious causes appeared to be equally distributed over the months. Among older people (panel B), infectious and non-infectious causes of death were equally common. Mortality from infectious causes in old age peaked in September with 74\% (95\% CI 0.97-2.87; $p=0.061$ ) higher mortality, whereas mortality from non-infectious causes peaked with $52 \%$ higher mortality in both September and April, (95\% CI $0.87-2.47 ; p=0.0138$.

\section{Discussion}

In a rural area in Ghana, we have observed a mortality peak in the wet season for both child and old-age mortality that can be explained by an increased number of deaths from infections. There was however, a second mortality peak at the end of the dry season among older people due to non-infectious causes. There was low mortality in the months succeeding the wet season.

Variation in mortality is both, driven by geographical factors such as climatic influences and by individual or household determinants. ${ }^{38}$ Therefore, we additionally studied the role of socioeconomic status and the use of (un)safe drinking water. Mortality during the wet season was higher for people from both rich and poor households. Although the effect size was similar for both groups, it was only significant in the (larger) group of the rich. By contrast, water source did influence the seasonal variation in mortality as indicated by the higher mortality during the wet season in individuals using unsafe drinking water. It is tempting to speculate that the observed excess mortality during the wet season in people drinking unsafe water could be explained by contamination of drinking water during the wet season, when unsafe open wells are flooded with surface water.

Climate could influence mortality via its effects on agriculture and disease transmission. Overall, it has been found that sub-Saharan African countries with long lasting rainy seasons
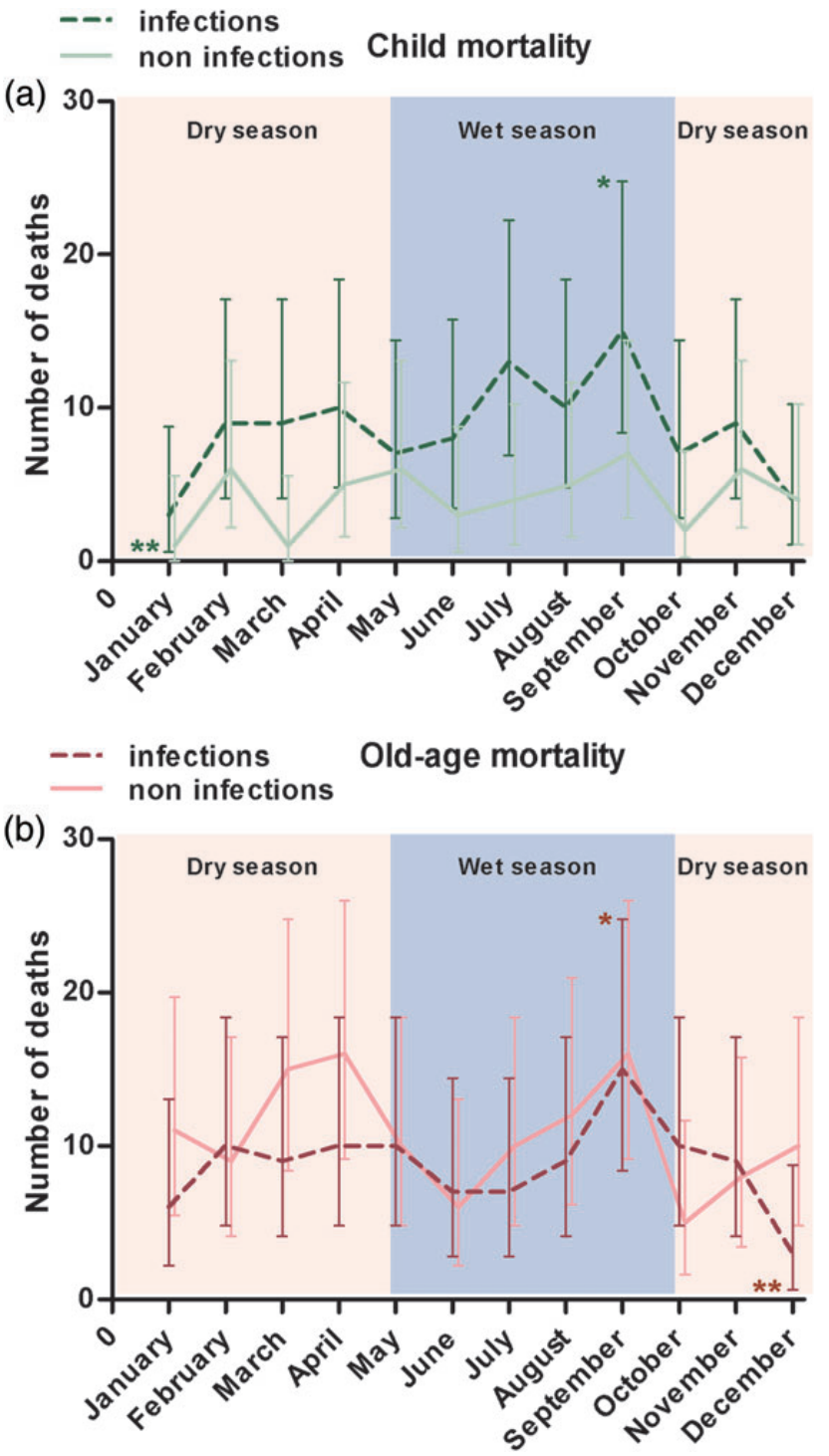

Figure 5. Seasonal variation in mortality from infectious and other causes in child mortality (panel A) and old-age mortality (panel B). Mortality is expressed as number of deaths per month with error bars indicating 95\% confidence interval. Stars indicate whether the observed number of deaths in that month are significantly higher than expected. ${ }^{*} \mathrm{p}<0.1,{ }^{* *} \mathrm{p}<0.05$.

have lower mortality rates when compared to countries that have shorter wet seasons. Most likely this is due to the fact that longer wet seasons foster agriculture and hence food abundance. ${ }^{38}$ In line with this interpretation we observed low mortality for all age groups in December and January, directly following the wet season. The increased mortality during the wet season has been mostly explained by an increase in gastrointestinal infections and malaria during that season. ${ }^{8,9,39,40}$ Our findings in the research area are in line with these data. Prior examination of our group has indicated that guinea worm, schistosomiasis and malaria have a high prevalence at the end of the wet season and the transmission of malaria is highest at that time. ${ }^{18,39}$ Compared to the dry season, the wet season shows increased parasitemia and severe anaemia rates in children. ${ }^{41}$ Since children 
and older people are most susceptible to malaria, these factors possibly contribute to the excess mortality at the end of the wet season that we have observed. ${ }^{40}$ Also, the incidence of gastrointestinal infections, skin infection and snake bites are higher during the wet season. ${ }^{40}$

The mortality peak during the wet season in September was driven by infectious diseases and affected children and older people alike. By contrast, mortality among older people showed a second peak during the dry season in April, due to non-infectious causes. The excess mortality for the elderly could be partly explained by the harsh conditions at the end of this season, when food is limited and expensive, as reflected in the prices of crop and livestock. ${ }^{23}$ This is however, not reflected in a higher mortality among children. Perhaps more important for older people, average temperature is highest at the end of the dry season in March and April. This will mostly affect older people with underlying cardiovascular diseases that are especially prone to heat-associated mortality. During the epidemiologic transition in the area, infectious diseases are decreasing together with an increase in the prevalence of chronic diseases, and this could well be reflected by a change in patterns of seasonal variation in mortality. Hence, the peak in September is most likely to decrease, whereas mortality among older people at the end of the dry season in April will probably increase in the future. This reasoning is supported by the observation that the peak in April was more prominent in recent years.

The clustering of mortality over calendar time is in line with earlier findings in the research area, where we have described significant clustering of mortality, dependent on family and household characteristics, such as socioeconomic status. ${ }^{42-45}$ Next to clustering on a geographical and family level we now show that mortality is clustering in time as well.

We believe that studying whether mortality is seasonal and in what months we can expect excess mortality are relevant research questions, especially in such a rural environment with high infection pressure. Further insights into the seasonal variation in mortality in rural Ghana can be a first step towards better prevention and public health. We believe we have shown that mortality is seasonal and the effect size, or amount of excess mortality occurs in specific months.

Several strengths and weaknesses of this study should be discussed. In a developing country with no available municipal registries, our longitudinal data set is a unique opportunity to study such a remote rural population. The verbal autopsy method is commonly used to assign causes of death in developing countries. ${ }^{46,47}$ A limitation of our study is that we performed the verbal autopsy interviews in 2011 with a maximum recall period of eight years. Large variations in recall period could influence the data and it has hence been recommended that verbal autopsies should be performed only within 2 years after the deaths occurred. ${ }^{48}$ However, in our data, the proportion of unspecified causes of deaths was not dependent on the recall period. This could be partly explained by the fact that we only distinguished within the broader categories of infectious versus non-infectious causes of death. An additional explanation could be that since the majority of the people in the study area are farmers and the seasons are clearly linked to distinct agricultural activities, most do not have difficulty in recalling the season of death. There was a moderate level of agreement between the adjudicating physicians, between the original interviews and the re-interviews, which we have considered acceptable given the nature of verbal autopsies. A further limitation is that we lack precise data on fertility and migration rates. If fertility would have a seasonal pattern, this could be reflected in the variation in mortality as well. Migration will have especially influenced our results in young adults, as at this age individuals are most likely to move in and out of the area. It is less plausible that this has influenced child and old-age mortality.

All in all, this study shows that during the epidemiologic transition in tropical countries, mortality not only shifts from child mortality to old-age mortality, and from infectious to noninfectious causes of death, but that the distribution of deaths over the seasons probably changes as well. A better understanding of seasonal variation in mortality is of prime importance for public health policies.

Authors' contributions: FE, UE, DvB and RW conceived the study; FE and UE designed the study protocol and collected data; FE and DVB performed the analysis and interpretation of these data. FE, JM and DvB drafted the manuscript; RW and UE critically revised the manuscript. All authors read and approved the final manuscript. RW is guarantor of the paper.

Acknowledgements: We thank the Ghana research team for their dedication and hard work during data collection in the field. Furthermore, we greatly appreciate the work of the physicians Shiva Prasad, Francesca Rosini, Raúl Hernán Medina Campos and Anna Boef for their help in assigning the causes of death. We thank Roger Blench for supplying the data on rainfall and temperature in the area. Finally, we would like to thank Jos Rohling for his assistance with the statistical analysis.

Funding: This research was supported by the Netherlands Foundation for advancements of Tropical Research (grant number WOTRO 93-467), the Netherlands Organization for Scientific Research (NOW 051-14-050), the EU funded Network of Excellence LifeSpan (FP6 036894), an unrestricted grant of the Board of the Leiden University Medical Center and Stichting Dioraphte. None of these organisations had any role in the design, analysis, interpretation or report of the study.

\section{Competing interests: None declared.}

Ethical approval: Approval was given by the Ethical Review Committee of the Ghana Health Service, the Medical Ethical Committee of the Leiden University Medical Centre in Leiden, the Netherlands and by the local chiefs and elders of the research area.

\section{References}

1 Mackenbach JP, Kunst AE, Looman CW. Seasonal variation in mortality in The Netherlands. J Epidemiol Commun H 1992;46:261-65.

2 Gemmell I, McLoone P, Boddy FA et al. Seasonal variation in mortality in Scotland. Int J Epidemiol 2000;29:274-79.

3 van Rossum CTM, Shipley MJ, Hemingway H et al. Seasonal variation in cause-specific mortality: are there high-risk groups? 25-year follow-up of civil servants from the first Whitehall study. Int J Epidemiol 2001;30:1109-16.

4 Telfar Barnard LF, Baker MG, Hales S et al. Excess winter morbidity and mortality: do housing and socio-economic status have an effect? Rev Environ Health 2008;23:203-21. 
5 Wilkinson P, Pattenden S, Armstrong B et al. Vulnerability to winter mortality in elderly people in Britain: population based study. BMJ 2004;329:647.

6 Healy JD. Excess winter mortality in Europe: a cross country analysis identifying key risk factors. J Epidemiol Commun H 2003;57:784-89.

7 Burkart K, Khan H, Krämer A et al. Seasonal variations of all-cause and cause- specific mortality by age, gender, and socioeconomic condition in urban and rural areas of Bangladesh. Int J Equity Health 2011;10:32.

8 Victora CG, Vaughan JP, Barros FC. The seasonality of infant deaths due to diarrheal and respiratory diseases in southern Brazil, 1974-1978. PAHO Bulletin 1985;19:29.

9 Shier RP, Dollimore N, Ross DA et al. Drinking water sources, mortality and diarrhea morbidity among young children in Northern Ghana. Trop Med Int Health 1996;1:334-41.

10 Romagosa C, Ordi J, Saute F et al. Seasonal variations in maternal mortality in Maputo, Mozambique: the role of malaria. Trop Med Int Health 2007;12:62-67.

11 Jaffar S, Leach A, Greenwood AM et al. Changes in the pattern of infant and childhood mortality in upper river division, The Gambia, from 1989 to 1993. Trop Med Int Health 1997;2:28-37.

12 Agyei-Mensah S, de-Graft Aikins A. Epidemiological transition and the double burden of disease in Accra, Ghana. J Urban Health: B New York Acad Med. 2010;87:879-97.

13 Rayco Solon P, Moore SE, Fulford AJ et al. Fifty year mortality trends in three rural African villages. Trop Med Int Health 2004;9:1151-60.

14 Omran AR. The epidemiologic transition: a theory of the epidemiology of population change. Milbank Mem Fund Q 1971;49:509-38.

15 Meij JJ, de Craen AJM, Agana J et al. Low-cost interventions accelerate epidemiological transition in Upper East Ghana. T Roy Soc Trop Med H 2009;103:173-78.

16 O'Meara PW, Mangeni J, Steketee R et al. Changes in the burden of malaria in sub-Saharan Africa. Lancet Infect Dis 2010;10:545-55.

17 Cogneau D, Rouanet L. Living conditions in Côte D'ivoire and Ghana, 1925-1985: what do survey data on height stature tell us? Econ Hist Develop Region 2011;26:55-82.

18 Ziem JB, Olsen A, Magnussen P et al. Distribution and clustering of Oesophagostomum bifurcum and hookworm infections in Northern Ghana. Parasitology 2006;132:525.

19 Boef AG, May L, van Bodegom D et al. Parasitic infections and immune function: Effect of helminth infections in a malaria endemic area. Immunobiology 2012;S0171:2.

20 FAO. Agroecological systems.Gateway to Land and Water Information Ghana. 2005. http://www.apipnm.org/swlwpnr/reports/y_sf/z_gh/gh. htm [accessed 18 July 2012].

21 Meij JJ, van Bodegom D, Laar Baya D. The Bimoba: The People of Yennu. In: JJ Meij Testing Life history theory in a contemporary African population. Thesis Leiden University, The Netherlands; 2007.

22 Kuningas M, May L, Tamm R et al. Selection for genetic variation inducing pro-inflammatory responses under adverse environmental conditions in a Ghanaian population. PloS One 2009;4:e7795.

23 Blench RM. LACROSREP II Working Paper: background conditions in the Upper East region, Northern Ghana; 2005.

24 IFAD. Upper East region Land Conservation and Smallholder Rehabilitation Report. 17, 1757; 2006.

25 Ministry of Food and Agriculture. Agriculture in Ghana, facts and figures 2009. 2010. Ghana, Statistics, Research and Information Directorate (SRID); 2010.

26 International Monetary Fund. World economic outlook October 2008. 1-11-2008. Washington, IFM Publication Services; 2008.
27 Peel MC, Finlayson BL, McMahon TA. Updated world map of the Köppen-Geiger climate classification. Hydrology and Earth System Sciences Discussions 2007;4:439-73.

28 Hayward D, Oguntoyinbo JS. Climatology of West Africa. Rowman \& Littlefield Publishers, Inc.; 1987.

29 WHO Library Cataloguing in Publication Data. Verbal autopsy standards: Ascertaining and attributing cause of death; 2007.

30 Chandramohan D, Maude GH, Rodriques LC et al. Verbal autopsies for adult deaths: their development and validation in a multi-centre study. Trop Med Int Health 1998;3:436-46.

31 Fauveau V. Assessing probable causes of death without death registration or certificates: a new science? B World Health Organ 2006;84:246-47.

32 Rutstein SO, Johnson K. The DHS wealth index (DHS Comparative Reports No. 6). Calverton: ORC Macro; 2004.

33 Van Bodegom D, May L, Kaptijn R et al. Socio-economic status by rapid appraisal is highly correlated with mortality risks in rural Africa. T Roy Soc Trop Med H 2009;103:795-800.

34 Cleveland RB, Cleveland WS, MCRae JE et al. STL: a seasonal-trend decomposition procedure based on loess. J Official Statistics 1990;6:3-73.

35 Garwood F. Fiducial limits for the poisson distribution. Biometrika 1936;28:437-42.

36 Patil VV, Kulkarni HV. Comparison of confidence intervals for the poisson mean: some new aspects. Commun Stat-theory Methods 1889;18:2393-2465.

37 Byar D. Unpublished data available on following website accessed January 2014: http://seer.cancer.gov/seerstat/WebHelp/Standardized_ Incidence_Ratio_and_Confidence_Limits.htm [accessed 3 January 2014].

38 Balk D, Pullum T, Storeygard A et al. A Spatial Analysis of Childhood Mortality in West Africa. Population Space Place 2004;10:175-216.

39 Becher H, Kynast-Wolf G, Sié A et al. Patterns of Malaria: Cause-specific and all-cause mortality in a malaria-endemic area of west africa. Am J Trop Med Hyg 2008;78:106-13.

40 Dowell SF. Seasonal variation in host susceptibility and cycles of certain infectious diseases. Emerg Infect Dis 2001;7:369-74.

41 Chambers R. Health, agriculture, and rural poverty: why seasons matter. The J Dev Stud 1982;18:217-38.

42 van Bodegom D, Rozing MP, May L et al. Socio-economic status determines sex dependent survival of human offspring. Evolution, Med Public Health 2013;1:37-45.

43 van Bodegom D, Eriksson UK, Houwing-Duistermaat JJ et al. Clustering of child mortality in a contemporary polygamous population in Africa. Biodemography Soc Biol 2012;58:162-72.

44 van Bodegom D, Rozing MP, May L et al. When grandmothers matter: A debate. Gerontology 2010;56:214-6.

45 Meij JJ, van Bodegom D, Ziem J et al. Quality-quantity tradeoff of human offspring under adverse environmental conditions. J Evolution Biol 2009;22: 1014-23.

46 Setel PW, Whiting DR, Hemed Y et al. Validity of verbal autopsy procedures for determining cause of death in Tanzania. Trop Med Int Health 2006;11:608-703.

47 Soleman N, Chandramaohan D, Shivuya K. Verbal autopsy: current practices and challenges. B World Health Organ 2006;84:239-45.

48 Snow RW, Basto De Azevedo I, Forster D et al. Maternal recall of symptoms associated with childhod deaths in rural east africa. Int $J$ Epidemiol 1993;22:677-83. 